\title{
Intercultural Business Communication and Translation:
}

\section{A 3-Dimensional Approach}

\author{
Despoina Panou (Ph.D. student) \\ School of Education, University of Leicester \\ 21 University Road, Leicester, LE1 7RF, U.K.
}

Tel: 30-697-810-8278 E-mail: despanou@yahoo.gr

Received: November 19, 2012

doi:10.5430/elr.v1n2p138
Accepted: December 9, 2012

Published: December 11, 2012

URL: http://dx.doi.org/10.5430/elr.v1n2p138

\begin{abstract}
The aim of the present paper is to explore the relation of intercultural business communication and translation. Having as theoretical background the writings of Edward Hall and Geert Hofstede, it is argued that intercultural business communication and translation are inextricably bound since translators act as mediators who facilitate communication between business people from different cultural and linguistic bacgrounds. In this article a three-dimensional view of business translation is proposed where it is claimed that there are three ways to look at business translation: (i) from the eyes of the student aspiring to become a successful translator, (ii) from the eyes of the professional translator, and (iii) from the point of view of the theorist who seeks to decipher the complex process of sense-making in multi-cultural and multi-linguistic business settings.
\end{abstract}

Keywords: Intercultural business communication, Business translation, Business discourse

\section{Intercultural Business Communication and Translation}

Issues of culture, language and their role in international business have been the focus of a growing number of theoretical and empirical studies. The phenomenal growth of international trade, the advances of technology and the Internet as well as the mobility and the diversity of the international labour force have all contributed to the popularity of the field of intercultural business communication in recent years. The rapidly growing field of international business communication has emphasized the fact that sensitivity to the variety of cultural differences is an important determinant for success in the contemporary competitive business arena. Moreover, the growing number of published books and articles in business-related journals as well as the emergence of business guides to specific cultures such as the Arab World (Nydell, 1987), Japan (March, 1988), Singapore (Leppert, 1990) etc. indicate the increasing interest in the discipline of intercultural business communication. As the term implies, intercultural business communication touches upon issues of culture, communication and business. According to Varner (2000:39) intercultural business communication is a unique construct different from other intercultural communication processes. In fact, Lovitt (1999) argues that business people who engage in intercultural business communication may not know everything about a specific culture but need to focus on the specific business context in order to communicate with their business partners.

It is worth mentioning that most of the work done on intercultural business communication has occurred in the last five decades following the pioneering work of the anthropologist Edward Hall $(1959,1966)$ and the social psychologist and engineer Geert Hofstede (1980). More specifically, the godfather of intercultural studies, Edward Hall in his famous books, The Silent Language (1959), The Hidden Dimension (1966) and Understanding Cultural Differences (1990) explored how the various cultures of the world affect people's verbal and non-verbal communication. Acknowledging the importance of context, he observes that meaning and context are intertwined and classifies societies according to a scale of low- and high-context. High-context (HC) communication is characterized as implicit, indirect, circular and coded whereas people in low-context (LC) cultures are more direct, open and communication is precise and result-focused. LC cultures tend to rely heavily on objective truth and reasoning while $\mathrm{HC}$ cultures believe that truth will be discovered through non-linear discovery processes (cited in Schmidt, 2007:40-41). 
Another important aspect of culture that is highly valued by Hall is that of time. In particular, Hall differentiates between monochronic and polychronic time, arguing that the different conceptualizations of time cause a considerable amount of frustration between people, and consequently, businessmen of different cultures. In monochronic societies, time is linear and is viewed as a tangible, real object. People concentrate on one given activity at a time and a set schedule must not be interrupted by extraneous events. Efficiency is highly valued and is measured through the 'use' of time, thus revealing the quantitative nature of linear time. For example, British, German and Scandinavian people are monochronic while people in Latin and Arab cultures are polychronic. The main characteristics of the latter are that they are familiarized with the fact that their work is subject to interruptions and are used to the simultaneous occurrence of many things (cited in Schmidt, 2007:44). Northern European cultures have been categorized as monochronic whereas Mediterranean cultures as polychronic. Although these dimensions were proposed in the 1960s and are frequently criticized for being outdated and archaic, a given culture may have a tendency to lean towards one value rather than the other.

Another groundbreaking book, which had an enormous influence on the further development of intercultural business communication, was published in 1980 by Hofstede called Culture's Consequences. In the late 1960s and early 1970s, while working at a multinational corporation, IBM, as a social scientist, he collected data from about 120,000 employees worldwide working at all levels and argued that the differences in their professional habits could mainly be attributed to national culture (cited in Schmidt, 2007:28). Based upon this study, he identified four central dimensions of cultural variation in work-related values, namely, individualism-collectivism, power-distance, uncertainty-avoidance, masculinity-femininity. Later, he added a fifth dimension, namely, short- and long-term orientation. In individualistic cultures, autonomy is the higher axiom and people are expected to look after themselves and their immediate families whereas in collectivist ones, they look after a wider group because their key values are loyalty and commitment. Now turning to the second dimension, in high power-distance cultures, inequalities are expected because the boss is autocratic and paternalistic and staff expects to be told what to do whereas in low power-distance ones, employees are relatively autonomous since the boss is uncomfortable with inequalities and acts as a "resourceful democrat" (cited in Schmidt, 2007:33). The uncertainty-avoidance dimension mainly focuses on the way people face the unknown. For instance, in the German culture, order and security is a must and structure is sought at all levels. On the other hand, cultures with low uncertainty-avoidance, such as Great Britain, tend to view uncertainty as part of life and are less risk averse. With respect to the fourth dimension, Japan, Mexico Germany and the US are considered to be masculine societies that value symbols like money, success and fearlessness (cited in Schmidt, 2007:38). On the opposite side, feminine societies (e.g. Sweden) centre on tender values such as care for others, harmony, quality of life and need for consensus (cited in Schmidt, 2007:38-39).

This sensitivity to intercultural differences as well as the need to be able to communicate successfully with others urges people to spend a lot of time and make considerable efforts to fit into their own culture. Understanding of our own cultural identity is a prerequisite before we can successfully engage in intercultural business communication (Jameson, 2007:199). The problem begins when people try to communicate with other people from another culture with different rules and values. And here lies the contribution of the translator who acts as the person who helps people from different cultural and linguistic groups to share knowledge and ideas. As Torop (2002:593) observes, translation and culture are inextricably bound since translation is embedded in the particular sociocultural context of a given language. It is through translation that dialogue becomes possible between linguistic communities and when this dialogue is business-oriented, the importance of translation cannot be overstressed (Blenkinsopp and Pajouh, 2010:43). Thus, it could be argued that translation functioning as a process of intercultural communication becomes a 'third' language' meant to alleviate differences between numerous meaning systems (Janssens, Lambert and Steyaert, 2004:420).

A close inspection of the aforementioned statement reveals the lack of singularity of meaning in all types of texts, including business and technical texts. In fact, Weiss (1997:327) wonders how there can be a single meaning yet numerous versions of that meaning that change according to the language, culture and target readership. For Weiss, a text can only be clear for a certain time and for a specific audience. Hence, translation cannot be simplistically defined as "information-transfer" but involves a familiarization process where the unfamiliar lexicon of business communication becomes familiar (Forman, 1998:53). Given the importance of translation in intercultural communication, I will now focus on business translation.

\section{Business Discourse and Translation: Some Theoretical Preliminaries}

One discipline from which business communication could gain valuable insights is translation. This is the case because communication is a vital part of business since the intended message to the customer must be conveyed 
accurately and correctly. Consequently, business success largely depends on effective communication between business partners and producers and consumers. In other words, translators must take into consideration the country's cultural, political, linguistic and social conditions in order to translate effectively the business message. A successful business translation will enable prospective buyers to understand the technicalities of the product and probably increase sales for the company. Hence, business communication can be significantly improved if the translator focuses on understanding and appreciating intercultural differences. Of course, business translation is a multi-faceted procedure and not a mere code-switching repetitive process since parameters such as time and cost play a significant role. More often than not, translators are required to produce translations under temporal constraints. In the real world, the phrase "to be finished by yesterday" is at the lips of the majority of managers, thus forcing translators to make trade-offs between reliability, speed and cost to the effect that the translator strives not to produce the perfect translation but only the best possible translation at a given time (Robinson, 1997:202). Hence, Robinson (1997) maintains that translators' reliability and success is not judged by their text fidelity but by their versatility, that is their ability to translate a wide range of texts, their adjustability to the needs of both the clients and the target readership, and finally, their sensitivity to cultural and linguistic differences (1997:12-14).

\section{A 3-Dimensional Approach to Business Translation}

There are potentially three ways to look at business translation; firstly, from the eyes of the student aspiring to become a successful translator, secondly, from the eyes of a professional translator, and lastly, from the point of view of the theorist who tries to come up with an attractive translation theory.

\subsection{A student's perspective}

In particular, looking at business translation from the student's perspective, it could be argued that the majority of them tries to acquire a basic understanding of business economics, business law, micro- and macro-economics as well as basic translation and writing skills. Perhaps the most distinguishing feature that seems to characterize all potential translators is their acknowledgement that business English, and consequently, business translation, is a difficult area to handle. Why is this case? The answer is quite straightforward. Not only do students have to stay up-to-date with current world events but they also have to think critically how these are interrelated with each other. As Svendsen (2001:39) observes they have to think how the earthquake in Kobe indirectly led to the collapse of one of the most famous UK merchant banks. Whereas students certainly benefit from reading business texts in the newspapers and journals in their effort to develop a "feel" for the language, Svendsen (2001: 41) argues that they fell trapped or even unable to escape from their word-by-word translations and produce functional translations. Their inability to fully understand the text or its background, their improper use of the source material and the lack of good dictionaries are some of the most frequent obstacles that most students stumble across in their attempt to produce good functional translations instead of word-for-word translations (Svendsen, 2001:41).

However, Svendsen points out (2001:41) that these difficulties can be overcome with "closer-to-real-life" exam assignments where students provide explanations about their choices of terminology, style, structure and critically discuss various aspects of the texts to be translated. Apart from critical thinking, translators must also have a firm knowledge of the conditions in both the countries of the source and target language as well as confidence to support their choices by watching attentively current developments in international business and combining theory with practice.

\subsection{A professional translator's perspective}

The problems professional translators face should not be underscored in any way. It should be specified that professionals fall into two categories, namely, that of language graduates who have acquired specialized research skills and have learnt a certain terminology and that of business graduates who have developed adequate foreign language proficiency. In other words, a good command of the source and target languages does not suffice in the case of business translation since knowledge of business terminology is a prerequisite. As Neubert has pointed out business texts demand a thorough understanding of the subject matter (2002:25). Despite mastery of the source and target language terminology, problems may well arise from the cultural and linguistic differences embedded in economic texts. In such cases, translators are not just required to import knowledge but also terminology. In this profession which is characterized by cut-throat competition, a successful translator is one who manages to enter new terms in the local jargon through their translation. Abu-Ssaydeh (1993:1) has noted that changes in the Arabian Gulf region have resulted into the coining of new terms from the part of the translators. Similarly, Chiper has observed (2002:231) in the Romanian translation of Principles of Marketing, words such as "marketer" and "marketing mix" have already entered the Romanian marketing jargon. Hence, as Chiper claims business translation may cause language change and/or innovation especially in countries that are not familiar with new financial realities 
(2002:231). A more dynamic approach to translation is taken by Forman (1998:57) who argues that translators are "privileged knowledge makers", thus defining and elaborating the direction of knowledge.

\subsection{A translation theorist's perspective}

The theorist's perspective is also of particular interest. Having realized the importance of communication in a variety of international situations, translation theorists are primarily interested in investigating the ensuing complexity of the sense-making process in multi-cultural and multi-linguistic business settings. In other words, the general issue that taunts the theorist is what translation can ask of and offer to business settings and vice versa (Stayaert and Janssens, 1997:131). But before such question is answered, the issue that should be firstly addressed is what business discourse is. In simple words, business discourse mainly deals with how people communicate strategically in business contexts (Bargiela-Chiappini, Nickerson, and Planken, 2007:3). More specifically, business discourse is viewed as a social action where focus is shifted on the investigation of different forms of professional communication ranging from business meetings to annual reports (Bargiela-Chiappini, Nickerson, and Planken, 2007:31). Although it is undeniable that many researchers have centered on English because of its prominent status as the international business language, it is true that a number of other European languages used in business communication have been studied closely such as German (Zilles 2004), French (Christian, 1998), Spanish (Charteris-Black and Ennis, 2001), Dutch (Wijst, 1996), Norwegian (Neumann, 1997), Danish (Grindsted, 1997) and Portuguese (Pereira, 2004). In addition to investigating English and other European languages in business discourse, researchers in the field have also studied the influence other disciplines including pragmatics, conversational analysis, discourse analysis, ethnography, and genre theory have in business discourse. For example, there are some researchers (e.g. Holmes, 2000) who view language as 'powerful action' and have systematically examined the relevance of status and the exercise of power in business organizations. Other researchers have emphasized on the inequalities and asymmetries in business settings, thus adopting a 'critical' approach to business discourse (Fairclough, 1993). But perhaps, the most fruitful area of research in business discourse has been that of intercultural business discourse where the emphasis is on how participants work together to find a solution in multi-lingual and multicultural business settings (Bargiela-Chiappini, Nickerson, and Planken 2007:27). In fact, Spencer-Oatey (2000, chapter 2) looks at parameters such as content, talk organization, body language and politeness and how these affect intercultural business communication (cited in Bargiela-Chiappini, Nickerson, and Planken 2007:27). More specifically, she has come up with the broader term "rapport" instead of politeness and claims that rapport management involves two main components, namely, the management of face and the management of sociality rights (cited in Bargiela-Chiappini, Nickerson, and Planken, 2007:42). According to her theory (2000:13-14), face is associated with personal/social value concerns whereas sociality rights focus on personal/social expectancies, thus reflecting people's concerns on social inclusion and/or exclusion (cited in Bargiela-Chiappini, Nickerson, and Planken, 2007:42).

Shifting away from the focus on the human factor in business discourse, many researchers (e.g. Garzone 2002, de Groot, Korzilius, Nickerson and Gerritsen 2006) have been intrigued by the effect of technology in the business world and have begun to move away from monomodality (e.g. the traditional printed business letter) to multimodality (e.g. commercial webpages). Their research on multimodality aims at deciphering not only linguistic but also non-linguistic aspects of the new multimedial communication environments. In fact, the digitization age has brought to the forefront new and more dynamic ways of communicating such as e-mails, chat rooms and intranets. More specifically, the importance of the Internet in business communication is widely acknowledged and a number of researchers (e.g. Boyd and Spekman 2001, MacDonald and Smith 2003, Eng 2004) have dealt with the impact of the Internet in various business contexts. In other words, through the use of the Internet, a business can have 24/7 information-sharing regardless of physical distance, thus achieving efficient communication both internally and externally. For instance, extranet, which is a type of internal communication network between business partners, enables company members to access corporate and technical data as well as product details and order information. According to Vlosky, Fontenot and Blalock (2000), such communication tools significantly reduce company costs and contribute productively to quick information-sharing.

More recent studies (e.g. Usunier and Roulin 2010, Kupritz and Cowell 2009, Markman 2009) have focused on the merits of online management communication, the discourse employed in chat-based virtual meetings and the language of business-to-business websites. In more detail, Usunier and Roulin (2010:189) argue that low-context communication style is more preferebable when it comes to the design and content of websites since messages are more easily readable, their use of color and graphics is more effective and their navigation tends to be more user-friendly. Similarly, in comparing online and face to face management communication, Kupritz and Cowell (2009:54) claim that whereas the benefits of face-to-face communication are widely appreciated, non-confidential information such as meeting times and system problems should be communicated through e-mail since it is more 
cost-effective. Moreover, in exploring the structure of interaction in chat-based virtual meetings, Markman (2009:150) concludes that business teams make use of specific linguistic devices in the openings and closings of their computer-mediated team meetings. Given the above, it could be argued that intercultural business communication has been revolutionalized with the advent of new media that encourages multimedial communication and emphasize multimodality. In this light, intercultural business communication could be defined as multimedial communication in multicultural business settings.

Besides moving from monomodality to multimodality, business discourse should also move to multidisciplinarity and engage into a cross-disciplinary dialogue (Bargiela-Chiappini, Nickerson, and Planken, 2007:67). Even though interdisciplinarity in business discourse is at its early stages there is a tendency from the part of business discourse researchers to engage into dialogue and collaborate with other researchers across disciplines (Bargiela-Chiappini, Nickerson, and Planken, 2007:67). In a similar manner, Forman (1998:66) points out that there are numerous ways for translators/researchers to achieve the extension of their research agenda and contribute to that of other disciplines. This interdisciplinary approach is also reinforced by the way Forman uses the term translation as a discursive activity enabling translators to become involved into a cross-cultural dialogue (Forman, 1998:56).

Taking the above into consideration, one might be prompted to think that the translation theorist may well be benefited from the dalogue between translators (professionals or not) in further deciphering what the translator's place in multi-lingual and multicultural organizations is. In particular, the theorist might want to examine the type of relationship translators have with their boss, the feedback they get, and more importantly, what they consider the purpose of the translation act to be. In other words, different expectations and norms govern different translators. More importantly, the strategy of the international firm also plays a crucial role in the translation management since a global integration strategy will 'demand' a different translation from a local strategy. Furthermore, the kind of technology used as well as the type of products and customers a particular company has also have a say in determining the translation policy adopted. The implication for both the translation student and the professional is that they need to acquire genre-based experience which will hopefully enable them to become sensitive to and aware of the distinctive features of business texts.

\section{Conclusion}

This study concludes with the suggestion that doing business translations is not a simple business since text function and translation function are not always the same. The decision to adhere to the literal or the free pole of translation will inevitably affect the end-product since equivalence tends to be a relative notion that is highly context-sensitive rather than a static concept (Hatim and Munday, 2004:261). Hence, the translation strategy adopted does not primarily rest on the source text but depends on the entire cultural context business texts are embedded in (Hatim and Munday, 2004:293) since word-for-word translation as well as 'free' translation can become equally powerful tools of ideology. This has practical implications for the training of translators since apart from domain-specific knowledge, which is mandatory, real-life experience is also a prerequisite. In fact, the role of the translator curricula in preparing translation students to enter the arena of professional translation is of utmost importance. Apart from teaching domain-specific terminology, translation students should acquire information-processing skills that will enable them to deal with the specific subject matter. The ability to check, edit, revise and use information does not solely rest on subject matter knowledge. Instead, perpective professional translators should gradually realize the hybrid nature of texts (electronic or not) and intercultural communication so as to be able to apply the appropriate problem-solving strategies. As Kastberg (2009:98) observes the change of focus from 'subject-matter expert' to personal-knowledge manager' points to the growing need of translation students to acquire life-long learning skills. In this respect, business translation could be viewed as a rather demanding, time-consuming process which requires both domain-specific knowledge as well as firm decision-making skills where various political, socio-economic, cultural and linguistic parameters should be taken into consideration.

\section{References}

Abu-Ssaydeh, A.F. (1993). Business translation. Babel. 39(1), 1-10. http://dx.doi.org/10.1075.babel.39.1.02.abu.

Bargiela-Chiappini, F., Nickerson, C. and Planken, B. (2007). Business Discourse. Basingstone: Palgrave Macmillan.

Blenkinsopp, J., Pajouh, M.S. (2010). Lost in translation? Culture, language and the role of the translator in international business. Critical Perspectives on International Business 6(1), 38-52. http://dx.doi.org/10.1108/17422041011017612. 
Boyd, D.E., Spekman, R.E. (2001). Internet usage within B2B relationships and its impact on value creation: a conceptual model and research propositions. Darden Graduate School of Business and Administration. Working Paper No. 01-17.

Charteris-Black, J. and Ennis, T. (2001). A comparative study of metaphor in Spanish and English financial reporting. English for Specific Purposes 15(1), 19-36. http://dx.doi.org/10.1016/S0889-4906(00)00009-0.

Chiper, S. (2002). Business translation. Perspectives: Studies in Translatology 10(3), 215-233. http://dx.doi.org/10.1080/0907676X.2002.9961446.

Christian, P. (1998). French and American business professionals: a discourse analysis study of cultural differences. Intercultural Communication Studies 8(2), 1-18.

Eng, T. (2004). Implications of the Internet for knowledge creation and dissemination in clusters of high-tech firms. European Management Journal 22(1), 87-98. http://dx.doi.org/10.1016/j.emj.2003.11.011.

Fairclough, N. (1993). Critical discourse analysis and the marketisation of public discourse: the universities. Discourse and Society 4, 133-68. http://dx.doi.org/10.1177/0957926593004002002.

Forman, J. (1998). More than survival: the discipline of business communication and the uses of translation. The Journal of Business Communication 35(1), 50-68. http://dx.doi.org/10.1177/002194369803500103.

Garzone, G. (2002). Describing e-commerce communication. Which models and categories for text analysis? In P. Evangelisti and E. Ventola (Eds.). English in Academic and Professional Settings. Techniques of Description/Pedagogical Applications. Monographic issue of Textus 15(2), 279-296.

Grindsted, A. (1997). Joking as a strategy in Spanish and Danish negotiations. In F. Bargiela-Chiappini, and S. Harris (Eds.). The Languages of Business. An International Perspective (pp. 159-182). Edinburgh: Edinburgh University Press.

Groot, E.B.d., Korzilius, H., Nickerson, C. and Gerritsen, M. (2006). A corpus analysis of text themes and photographic themes in managerial forewords of Dutch-English and British annual general reports. IEEE Transactions on Professional Communication. September 2006, 217-236. http://dx.doi.org/10.1109/TPC.2006.880755.

Hall, E. (1959). The Silent Language. New York: Doubleday.

Hall, E. (1966). The Hidden Dimension. New York: Doubleday.

Hall, E.T. (1990). Understanding Cultural Differences. Germans, French and Americans. Yarmouth: Intercultural Press.

Hatim, B. and Munday, J. (2004). Translation. An Advanced Resource Book. London and New York: Routledge.

Hofstede, G.H. (1980). Culture's Consequences: International Differences in Work-Related Values. Beverly Hills, CA: Sage.

Holmes, J. (2000). Victoria University's language in the workplace project: an overview. Language in the Workplace Occasional Papers 1.

Jameson, D.A. (2007). Reconceptualizing cultural identity and its role in intercultural business communication. Journal of Business Communication 44(3), 199-235. http://dx.doi.org/10.1177/0021943607301346.

Janssens, M., Lambert, J. and Steyaert, C. (2004). Developing language strategies for international companies: the contribution of translation studies. Journal of World Business 39(4), 414-430. http://dx.doi.org/10.1016/j.wb.2004.08.006.

Kastberg, P. (2009). Personal knowledge management in the training of non-literary translators. The Journal of Specialized Translation 11, 88-102.

Kupritz, V.W. and Cowell, E. (2009). Productive management communication online and face-to-face. Journal of Business Communication 48(1), 54-82. http://dx.doi.org/10.1177/0021943610385656.

Leppert, P. (1990). Doing Business with the Koreans: A Handbook for Executives. Chula Vista, Calif: Patton Pacific Press.

Lovitt, C.R. (1999). Rethinking the role of culture in international professional communication. In C.R. Lovitt and D. Goswami (Eds.). Exploring the Rhetoric of International Professional Communication (pp.1-16). New York: Baywood. 
MacDonald, J.B. and Smith, K. (2003). The effects of technology-mediated communication on industrial buyer behavior. Industrial Marketing Management 33, 107-116. http://dx.doi.org/10.1016/S0019-8501(03)00033-6.

March, R.M. (1988). The Japanese Negotiator: Subtlety and Strategy Beyond Western Logic. Tokyo: Kodansha International.

Markman, K.M. (2009). "So what shall we talk about". Openings and closings in chat-based virtual meetings. Journal of Business Communication 46(1), 150-170. http://dx.doi.org/10.1177/0021943608325751.

Neubert, A. (2002). Theory and practice of translation revisited: 25 years of translation training in Europe. In A. Beeby, D. Ensinger and M. Presas (Eds.). Investigating Translation. Selected Papers from the Fourth International Congress on Translation (pp.13-26). Barcelona, 1998. Amsterdam and Philadelphia: John Benjamins.

Neumann, I. (1997). Requests in German-Norwegian business discourse: differences in directness. In F. Bargiela-Chiappini and S. Harris (Eds.). The Languages of Business. An International Perspective (pp.72-93). Edinburgh: Edinburg University Press.

Nydell, M. (1987). Understanding Arabs: A Guide for Westerners. Yarmouth, Maine: Intercultural Press.

Pereira das Gracas Dias, M. (2004). Constructing identities and searching for partnerships in a meeting of Portuguese and Brazilian businessmen. In C. Gouveia, C. Silvestre and L. Azuga (Eds.). Discourse, Communication and the Enterprise (pp.169-194). Lisbon: ULICES, University of Lisbon.

Robinson, D. (1997). Becoming a Translator. An Introduction to the Theory and Practice of Translation. $2^{\text {nd }}$ edition. London and New York: Routledge.

Schmidt, P.L. (2007). In Search of Intercultural Understanding. Austria:Meridian World Press.

Spencer-Oatey, H. (2000). Culturally Speaking. Managing Rapport Through Talk Across Cultures. London: Continuum.

Stayaert, C. and Janssens, M. (1997). Language and translation in an international business context: beyond an instrumental approach. Target 9(1), 131-154. http://dx.doi.org/10.1075/target.9.1.08ste.

Svendsen, (2001). Economic translation - how to put theory into practice. In Proceedings from the First International Conference on Specialized Translation (pp.39-41). Universitat Pompeu Fabra, Barcelona 2-4 March 2000. Universitat Pompeu Frabra.

Torop, P. (2002). Translation as translating as culture. Sign System Studies 30(2), 593-605.

Varner, I.I. (2000). The theoretical foundation for intercultural business communication: a conceptual model. The Journal of Business Communication 37(1), 39-57. http://dx.doi.org/10.1177/002194360003700102.

Vlosky, R.P., Fontenot, R.and Blalock, L. (2000). Extranets: impacts on business practice and relationships. Journal of Business and Industrial Marketing 15(6), 438-457. http://dx.doi.org/10.1108/08858620010349510.

Usunier, J.C. and Roulin, N. (2010). The influence of high- and low-context communication styles on the design, content and language of business-to-business web sites. Journal of Business Communication 47(2), 189-227. http://dx.doi.org/10.1177/0021943610364526.

Weiss, T. (1997). Reading culture. Professional communication as translation. Journal of Business and Technical Communication 11(3), 321-338. http://dx.doi.org/10.1177/1050651997011003005.

Wijst, P. van der. (1996). Politeness in requests and negotiations. Dordrecht: ICG Printing B.V.

Zilles, S. (2004). Offers in German and Irish English business negotiations. A cross-cultural empirical analysis of micropragmatic and macropragmatic aspects. Paper delivered at the ABC European Conference, Milan, 22 May. 